\title{
Reduced error monitoring in children with autism spectrum disorder: an ERP study
}

Citation for published version (APA):

Vlamings, P. H. J. M., Jonkman, L. M., Hoeksma, M., van Engeland, H., \& Kemner, C. (2008). Reduced error monitoring in children with autism spectrum disorder: an ERP study. European Journal of Neuroscience, 28 (2), 399-406. https://doi.org/10.1111/j.1460-9568.2008.06336.x

Document status and date:

Published: 01/01/2008

DOI:

10.1111/j.1460-9568.2008.06336.x

Document Version:

Publisher's PDF, also known as Version of record

Document license:

Taverne

Please check the document version of this publication:

- A submitted manuscript is the version of the article upon submission and before peer-review. There can be important differences between the submitted version and the official published version of record.

People interested in the research are advised to contact the author for the final version of the publication, or visit the DOI to the publisher's website.

- The final author version and the galley proof are versions of the publication after peer review.

- The final published version features the final layout of the paper including the volume, issue and page numbers.

Link to publication

\footnotetext{
General rights rights.

- You may freely distribute the URL identifying the publication in the public portal. please follow below link for the End User Agreement:

www.umlib.nl/taverne-license

Take down policy

If you believe that this document breaches copyright please contact us at:

repository@maastrichtuniversity.nl

providing details and we will investigate your claim.
}

Copyright and moral rights for the publications made accessible in the public portal are retained by the authors and/or other copyright owners and it is a condition of accessing publications that users recognise and abide by the legal requirements associated with these

- Users may download and print one copy of any publication from the public portal for the purpose of private study or research.

- You may not further distribute the material or use it for any profit-making activity or commercial gain

If the publication is distributed under the terms of Article $25 \mathrm{fa}$ of the Dutch Copyright Act, indicated by the "Taverne" license above, 


\title{
Reduced error monitoring in children with autism spectrum disorder: an ERP study
}

\author{
Petra H. J. M. Vlamings, ${ }^{1}$ Lisa M. Jonkman, ${ }^{1}$ Marco R. Hoeksma, ${ }^{2}$ Herman van Engeland ${ }^{2}$ and Chantal Kemner ${ }^{1,2}$ \\ ${ }^{1}$ Department of Neurocognition, Faculty of Psychology, Universiteit Maastricht, The Netherlands \\ ${ }^{2}$ Department of Child and Adolescent Psychiatry, University Medical Center, Utrecht, The Netherlands
}

Keywords: ACC, ERN, ERP, Pe, self-monitoring

\begin{abstract}
This study investigated self-monitoring in children with autism spectrum disorder (ASD) with event-related potentials looking at both the error-related negativity (ERN) and error-related positivity $(\mathrm{Pe})$. The $\mathrm{ERN}$ is related to early error/conflict detection, and the Pe has been associated with conscious error evaluation or attention allocation. In addition, post-error slowing in reaction times (RTs) was measured. Children with ASD and age- and IQ- matched controls were administered an easy and a hard version of an auditory decision task. Results showed that the ERN was smaller in children with ASD but localized in the anterior cingulate cortex (ACC) in both groups. In addition we found a negativity on correct trials (CRN) that did not differ between the groups. Furthermore, a reduced $\mathrm{Pe}$ and a lack of post-error slowing in RTs were found in children with ASD. The reduced ERN in children with ASD, in the presence of an intact CRN, might suggest a specific insensitivity to detect situations in which the chance of making errors is enhanced. This might in turn lead to reduced error awareness/attention allocation to the erroneous event (reduced $\mathrm{Pe}$ ) and eventually in a failure in change of strategy to deal with a situation, as becomes evident from the lack of post-error slowing in the ASD group. This relates well to the perseverative behaviour that is seen in children with ASD. We discuss these results in terms of a general deficit in self-monitoring, underlying social disturbance in ASD and the involvement of the ACC.
\end{abstract}

\section{Introduction}

Autism spectrum disorder (ASD) is a severe developmental disorder, characterized by impairments in social interaction and communication, and restricted behaviour and interests (American Psychiatric Association, 1994). The relation between specific brain abnormalities and atypical behaviour in ASD is still unclear. Recently, Allman et al. (2005) found abnormal concentrations of spindle neurons in subjects with autism. Spindle neurons are large, bipolar cells located in layer five of the anterior cingulate cortex (ACC) and frontoinsular cortex. It is hypothesized that spindle cells play a crucial role in the integration of reward and punishment probabilities (Allman et al., 2005), which is important in the ability to monitor and self-correct one's own thoughts and actions. Some studies have indeed shown a relation between ACC activity and adaptive behaviour, especially the ability for selfmonitoring (Hajcak et al., 2003; Amiez et al., 2006). Several behavioural features in autism, like perseverative responding and an inability to adapt in social situations, may reflect impaired selfmonitoring, which could be related to abnormal functioning of the ACC (Rusell, 1997; Mundy, 2003; Hill, 2004; Henderson et al., 2006).

Indeed, decreased metabolism of the ACC has been reported in subjects with ASD (Haznedar et al., 1997, 2000). Furthermore, children with ASD have difficulties in error correction and avoidance, which is suggestive of impaired self-monitoring (Rusell \& Jarrold, 1998), although a monitoring deficit was not found in a second study (Rusell \& Hill, 2001). However, so far there have been no studies in which ACC functioning was directly measured during self-monitoring behaviour in children with ASD.

Correspondence: Dr P. Vlamings, as above.

E-mail: p.vlamings@psychology.unimaas.nl

Received 15 October 2007, revised 19 May 2008, accepted 21 May 2008
Prominent in research on self-monitoring and ACC functioning are event-related brain potential (ERP) studies on self-monitoring. Selfmonitoring is reflected in the so-called error-related negativity (ERN) and error-related positivity $(\mathrm{Pe})$, which occur after an error has been made. In adults, the ERN peaks $50-100 \mathrm{~ms}$ after an erroneous response. Although the function of the ERN is still under debate, current theories interpret the ERN as reflecting the detection of postresponse conflict or mismatch between the actual (erroneous) response and the competing correct response tendency (Coles et al., 2001; Yeung et al., 2004; Ullsperger \& von Cramon, 2006). Recently the ERN has been ascribed a more general evaluative function, reflecting the outcome of a broad action-regulation system signalling expectancy violations (see, for review, Wiersema et al., 2007). The Pe has a centroparietal distribution and follows the ERN about $200-500 \mathrm{~ms}$ after response, and has been related to error awareness and the adjustment of response strategies, such as post-error slowing in reaction times (RTs; e.g. Leuthold \& Sommer, 1999; Falkenstein et al., 2000; Hajcak et al., 2003). Dipole localization analyses (Luu et al., 2000; van Veen \& Carter, 2002; Hermann et al., 2004; O'Connell et al., 2007) as well as functional magnetic resonance imaging (fMRI; e.g. Carter et al., 1998; Ullsperger \& von Cramon, 2001) and magnetoencephalography (MEG) studies (Miltner et al., 2003) have convincingly associated both ERN and Pe activity with ACC functioning.

In the present study we aim to directly relate $\mathrm{ACC}$ functioning in children with ASD, as reflected in specific ERP peaks, to abnormal self-monitoring. Based on the literature, which describes indications for ACC dysfunction as well as deficits in self-monitoring in ASD, we expect behavioural impairments in error processing as well as abnormalities in the ERN and Pe. Given the large individual differences in social symptoms in ASD, we explored the link between 
symptoms of ASD on the one hand and ERN, Pe and post-error slowing on the other. Given that previous studies found a relation between intellectual functioning and self-monitoring (Rabbitt, 1990; Henderson et al., 2006), we also examined the relation between IQ and the ERN, Pe or post-error slowing.

\section{Materials and methods Participants}

A total of 18 controls and 25 ASD children took part in this study. From the control group one child was excluded because of bad electroencephalographic (EEG) data, one because of misunderstanding the task and six because of not passing the criteria of five error trials, which was necessary to be included in the analysis. From the ASD group, one child was excluded because of unclear diagnosis and seven children were excluded because of not passing the criteria of six error trials. The final group consisted of 10 control children (ratio male : female: 10 : 0 ; mean age: 9.23 years; SD: 1.20 ) and 17 children with ASD (ratio male : female: 16 : 1; mean age: 10.42 years; SD: 2.04). Clinical and comparison participants were matched on age at the group level $\left(F_{1,25}=0.962, P=0.336\right)$. The children with ASD were recruited from the Department of Child and Adolescent Psychiatry at the Utrecht Academic Hospital. Controls were recruited from elementary schools in and around Utrecht, and had no history of medical or psychiatric problems. Groups did not differ in IQ (Wechsler Intelligence Scale for Children (WISC-RN; Table 1). All diagnoses were based upon DSMIV criteria and were made by a child psychiatrist after extensive diagnostic evaluation, including a review of prior records (developmental history, child psychiatric and neurological observations, and tests and neurological investigations). The patients' diagnosis was either autism $(n=10)$ or Asperger syndrome $(n=7)$, based on DSMIV criteria (American Psychiatric Association., 1994) and ADI-R (Lord et al., 1994). The ADI-R is a semi-structured interview for caregivers of children and adults with ASD, and consists of three domains: (a) quality of social interaction; (b) communication and language; and (c) repetitive, restricted and stereotyped interests (Lord et al., 1994). Two of the patients with Asperger syndrome did not meet the strict ADI criteria for autism on one of the domains. All subjects were medication free (medication was never prescribed) and had no significant neurological history. The experiment was approved by the local ethical committee and parents gave written informed consent. The study conformed with the Code of Ethics of the World Medical Association (Declaration of Helsinki) and was approved by the Ethical Committee of Psychology, University Maastricht.

\section{Tasks}

The current study is part of a larger project on executive functioning in children and adults with ASD by Hoeksma et al. (2004). The dual task

TABLE 1. Full-scale, performance and verbal IQ scores for ASD children and controls

\begin{tabular}{llll}
\hline & Full-scale IQ & Performance IQ & Verbal IQ \\
\hline ASD & $94.5 \pm 16.2$ & $99.19 \pm 17.9$ & $92.19 \pm 15.3$ \\
& $(61-120)$ & $(59-129)$ & $(64-112)$ \\
Controls & $95.1 \pm 12.5$ & $100.6 \pm 14.3$ & $90.8 \pm 10.8$ \\
& $(81-116)$ & $(73-118)$ & $(77-114)$ \\
\hline
\end{tabular}

ASD, autism spectrum disorder. Data are means \pm SD (range in parentheses). design was chosen in light of this study to investigate processing capacity in children and adults with ASD. It is unrelated to the rationale behind the present study, which investigates self-monitoring related to ACC functioning. In this paper only the electrophysiological measures relevant for error processing are reported, the other components that are elicited by the auditory decision task have been reported elsewhere (Hoeksma et al., 2004).

In the task, the participants were administered an easy and a hard version of an auditory decision task, each consisting of two blocks. In the easy task, each block contained 70 task stimuli, which were animal sounds of a cat, dog, sheep and pig. These stimuli were presented binaurally through in-ear phones, at a level of $95 \mathrm{~dB}$. In the easy task, the subject's instruction was to press a right-hand button whenever a cat sound was presented and a left-hand button for every other sound. In this condition there were 34 cat sounds and 36 non-cat sounds for each block to ensure approximately as many right- as left-hand button presses. In the hard task, the animal sounds were evenly divided. In this condition, the subject's task was to compare each sound that was presented with the preceding sound. When the sound was the same as the preceding sound, the subject was instructed to press the right-hand button. When the sounds were dissimilar, the left-hand button was to be pressed. To ensure as many right- as left-hand button presses, the probability that two successive stimuli were (dis-) similar was $50 \%$. Thus, for proper execution of this task condition, subjects had to keep a running memory of presented stimuli. In both the easy and hard condition all auditory task stimuli were task relevant, as they all required either a right- or left-hand button press. Visual probes were presented in the centre of a computer screen, in between presentations of auditory task stimuli. There were 70 probe stimuli per block, divided into three stimulus types. Standards $(60 \%)$ were abstract figures, composed of black and white squares. The information value of each figure was 80 bits (Attneave, 1954). Deviants (20\%) were adapted from the standard stimuli, but the stimuli were divided into four evenly large quadrants, which were each mirrored and rotated $180^{\circ}$. Novels $(20 \%)$ were unique abstract-coloured patterns. Each novel occurred only once in the entire experimental session. All visual stimuli were presented on a computer monitor, which was positioned at about $1 \mathrm{~m}$ from the subject's eyes. Standard and deviant probes subtended a height of $5.7^{\circ}$ of arc and a width of $11^{\circ}$ of arc. Novels subtended a height of $10.5^{\circ}$ of arc and a width of $11.75^{\circ}$ of arc. All stimuli were presented with a duration of $0.3 \mathrm{~s}$. Interstimulus intervals (ISIs) between primary (auditory) task stimuli were randomized between 4.2 and $5.4 \mathrm{~s}$. Probe stimuli were presented following a task stimulus with an ISI varying randomly between 1.95 and $2.55 \mathrm{~s}$. Subjects were told that in between task stimuli, pictures would appear on the screen; these required careful attention, but no response. Instructions for the tasks were given orally, and the subject had to perform a short practice series during which the experimenter followed the subject's responses on-line. When the experimenter was convinced that task requirements were met, the subject was instructed to move as little as possible during the task and to keep his eyes fixed on a crosshair on the centre of the computer screen. After each task block, the experimenter entered the room and gave instructions for the next block.

\section{Electrophysiological recording, data reduction, source analysis and statistical analysis}

The EEG was recorded with a 62-channel electrode cap, including a left mastoid reference. EEG epochs were extracted beginning $1100 \mathrm{~ms}$ before and ending $900 \mathrm{~ms}$ after each response using the 
SCAN software package (Neuroscan, version 4.2). The epochs were band-pass filtered with a $30 \mathrm{~Hz}, 24 \mathrm{~dB} /$ octave low-pass filter and baseline corrected using a pre-response window of -1100 to $-900 \mathrm{~ms}$. Vertical eye movements and blinks were removed from the data by application of a linear regression procedure (Semlitsch et al., 1986). In a next step epochs containing artefacts exceeding $125 \mu \mathrm{V}$ were excluded from further data analyses. To ensure enough error trials for analyses; the data from easy and hard tasks were combined. Finally, to quantify the ERN and the Pe, the epochs were averaged time-locked to the response, separately for trials to which subjects responded correctly and incorrectly. The mean number of trials that went into the averages for correct and incorrect trials were 171 (SD: 64) and 13 (SD: 7) for controls, and 178 (SD: 57) and 15 (SD: 8) for children with ASD. There was no significant difference between the groups with respect to the number of correct and incorrect trials. It was recently pointed out (Thomas et al., 2004) that when fewer than 27 trials are used for averaging of ERPs, the signalto-noise ratio is low and this results in systematic overestimation of peak amplitudes. This might be the case with respect to erroneous responses, as few trials went into the averages compared with correct responses. In the present study, however, we used mean areas because they do not become biased by differences in signal to noise ratio and are therefore allowed to use when comparing conditions containing unequal numbers of trials (Luck, 2005). In addition to using mean areas, we checked whether we could replicate our results when comparing incorrect trials with a set of randomly selected correct trials, which were matched in number to the number of incorrect trials. This was the case for all of our analysis (see Table 2). Finally, given the small number of erroneous trials needed to be included in the analysis $(n>5)$ and the known influence of number of trials on average ERP amplitude, we explored whether there was a relationship between the number of trials and the size of the ERN and Pe. We did not find evidence for this and therefore did not include number of trials as a covariate in our analysis.

TABLE 2. Results of the three-way ANOVA with factor Trial Type (correct/ incorrect), Electrode (ERN: Fz, FCz and Pe: Cz, Pz) and Group (controls/ASD)

\begin{tabular}{lllr}
\hline Source & df & $F / t$ & $P$ \\
\hline $\begin{array}{l}\text { ERN } \\
\text { Three-way ANOVA (Fz, FCz) }\end{array}$ & & & \\
$\quad$ Trial type $\times$ group & 1,25 & $F=5.54$ & 0.03 \\
$\quad$ Electrode & 1,25 & $F=27.05$ & $<0.001$ \\
& & & \\
Trial type per group & 1,16 & $F=0.15$ & 0.71 \\
$\quad$ ASD: correct-error & 1,9 & $F=6.58$ & 0.03 \\
$\quad$ Controls: correct-error & & & \\
Group per trial type & 25 & $t=-3.12$ & $<0.01$ \\
$\quad$ Error: controls-ASD & 25 & $t=-0.78$ & 0.44 \\
$\quad$ Correct: controls-ASD & & & \\
$\quad \begin{array}{l}\text { Pe } \\
\text { Three-way ANOvA (Cz, Pz) }\end{array} \quad 1,25$ & $F=0.26$ & $<0.01$ \\
$\quad$ Trial type $\times$ group & 1,25 & $F=0.17$ & 0.04 \\
$\quad$ Electrode & & & \\
$\quad$ Trial type per group & 1,9 & $F=12.46$ & $<0.01$ \\
$\quad$ ASD: correct-error & & & \\
$\quad$ Controls: correct-error & 1,16 & $F=0.267$ & 0.03 \\
\hline
\end{tabular}

Instead of including all correct trials, mean amplitudes for the correct trial type were based on a random set of correct trials, matched in number to the number of incorrect trials for each subject. ASD, autism spectrum disorder; ERN, errorrelated negativity.
We measured the amplitude of the ERN by computing the difference between the mean area amplitude in a window surrounding the first positive peak preceding the response (mean area: $110-50 \mathrm{~ms}$ before the response), and the mean area amplitude surrounding the first negativity after the response (mean area $30-70 \mathrm{~ms}$ ) at $\mathrm{Fz}$ and $\mathrm{FCz}$ for correct and incorrect averages separately. We analysed the ERN using a 2 (Group: ASD/control) $\times 2$ (Trial Type: correct/error) $\times 2$ (Electrode: $\mathrm{Fz} / \mathrm{FCz}$ ) mixed ANOvA. The amplitudes of the Pe (mean area measure: $250-500 \mathrm{~ms}$ after response at $\mathrm{Cz}$ and $\mathrm{Pz}$; Fig. 1) were measured per lead, using a 2 (Group: ASD/control) $\times 2$ (Trial Type: correct/error) $\times 2$ (Electrode: $\mathrm{Pz} / \mathrm{Cz})$ mixed ANOVA.

Post-error slowing in RTs was analysed by comparing the mean RT of correct trials following either correct or error trials [2 (Group: ASD/control) $\times 2$ (Slowing: correct-correct; error-correct) mixed ANOVA]. Furthermore, planned contrasts were performed to test the hypotheses that controls would show significant post-error slowing, whereas children with ASD would not.

For the ERN, Pe as well as post-error slowing, we investigated whether there was a significant correlation with total IQ scores, verbal IQ scores and performal IQ scores as well as symptom presentation on the three domains of the ADI-R using Pearson-R.

To explore whether the sources of the ERN could be localized to the same brain region (ACC) in children with ASD and controls, for each group (ASD/Controls) the locations of the neural generators for the ERN were modelled on the grand-average average-referenced ERN data for incorrect responses, using Brain Electrical Source Analysis software (BESA2000; www.besa.de). For source modelling a fourshell ellipsoidal head model was used. Because bone thickness and conductivities are age dependent, the default (adult) values were adjusted to $5.7 \mathrm{~mm}$ for bone thickness and 0.012 for bone conductivity. All reported dipole solutions were obtained without constraints and were stable across randomly varying starting positions.

\section{Results}

\section{RTs: post-error slowing}

Controls and children with ASD did not differ in the number of errors [controls: 14.4 (SD: 7.23; range: 6-29); ASD: 21.41 (SD: 13.34; range: 5-60)] or in mean RT [controls: $919 \mathrm{~ms}$ (SD: $196 \mathrm{~ms}$ ); ASD: $973 \mathrm{~ms}$ (SD: $98 \mathrm{~ms}$ )]. Planned contrasts indicated significant posterror slowing in controls only $\left(t_{9}=2.472 ; P<0.05\right)$. In controls, the mean RT for correct trials was significantly longer following error trials than following correct trials (mean difference: $69 \mathrm{~ms}$; SD: $88 \mathrm{~ms}$ ). In children with ASD slowing was not significant (mean difference: $20 \mathrm{~ms}$; SD: $103 \mathrm{~ms}$ ). There was no relationship between post-error slowing and IQ measures or symptom presentation.

\section{ERN}

Analysis of the three-way ANOVA indicated a significant interaction between Trial Type and Group $\left(F_{1,25}=7.99, P<0.01\right)$, suggesting that the difference between correct and incorrect trials differed between the groups. Further analysis of this interaction showed that there was a significant difference between correct and incorrect trials in controls only $\left(F_{1,9}=8.35, P<0.05\right)$. Children with autism showed a smaller ERN compared with controls $\left(t_{25}=-3.11, P<0.01\right)$, whereas there was no group difference in negativity with respect to correct responses (see Fig. 1 and Table 3). Finally, there was a main effect of electrode $\left(F_{1,25}=16.72 ; P<0.001\right)$ with larger amplitudes for $\mathrm{FCz}$ than $\mathrm{Fz}$ in children with autism as well as controls. There was no relationship between ERN amplitude and IQ measures or symptom presentation. 


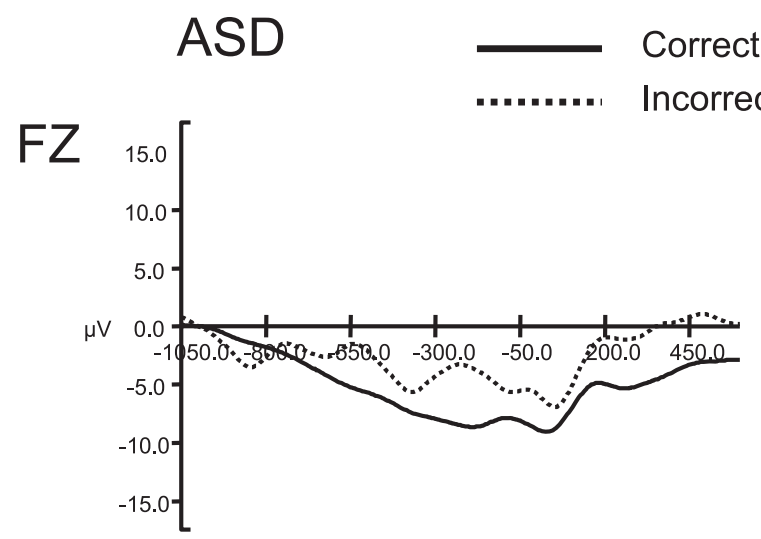

\section{Controls}
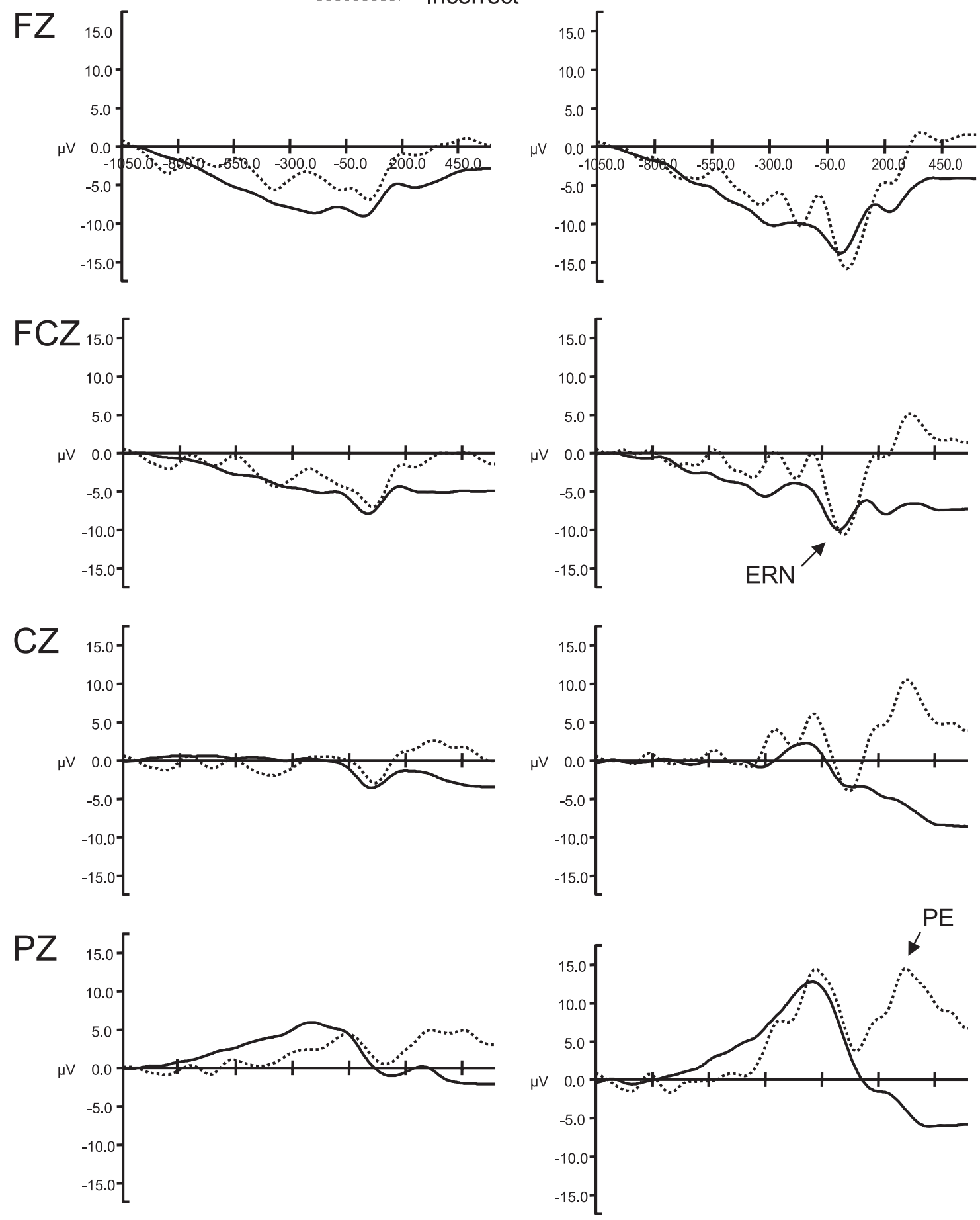

FIG. 1. Grand-averaged response-locked waveforms for normal controls and children with autism spectrum disorder (ASD). ERN, error-related negativity; Pe, errorrelated positivity.

Importantly, as the ERN was measured peak-to-peak (with a mean area measure around the peaks), we checked whether the difference in ERN activity between children with ASD and controls could be explained by a group difference in the initial positivity, that took place prior to responding. Results showed that children with autism and controls did not differ in the initial positivity at $\mathrm{Fz}$ or $\mathrm{FCz}$ on correct as well as incorrect trials.
Pe

Analysis of the three-way ANOVA indicated a significant interaction between Group and Trial Type irrespective of electrode $\left(F_{1,25}=7.97\right.$, $P<0.01)$. Both controls and children with ASD showed a larger positivity after an error than a correct response (Controls: $F_{1,9}=21.09, P=0.01 ;$ ASD: $\left.F_{1,16}=6.07, P<0.05\right)$. This effect was, however, reduced in children with ASD (see Fig. 1 and Table 3). 
TABLE 3. ERN and the Pe amplitudes (areas) on correct and incorrect trials for children with ASD and controls

\begin{tabular}{|c|c|c|c|c|}
\hline & \multicolumn{2}{|l|}{ Correct } & \multicolumn{2}{|l|}{ Incorrect } \\
\hline & $\mathrm{Fz}$ & $\mathrm{FCz}$ & $\mathrm{Fz}$ & $\mathrm{FCz}$ \\
\hline \multicolumn{5}{|c|}{ ERN amplitude $(\mu \mathrm{V})$} \\
\hline Controls & $-2.24 \pm 4.81$ & $-5.16 \pm 4.12$ & $-11.67 \pm 9.99$ & $-12.89 \pm 10.99$ \\
\hline \multirow[t]{3}{*}{ ASD } & $-1.49 \pm 4.46$ & $-3.12 \pm 4.26$ & $-1.57 \pm 6.52$ & $-3.01 \pm 6.66$ \\
\hline & \multicolumn{2}{|l|}{ Correct } & \multicolumn{2}{|l|}{ Incorrect } \\
\hline & $\mathrm{Cz}$ & $\mathrm{Pz}$ & $\mathrm{Cz}$ & $\mathrm{Pz}$ \\
\hline \multicolumn{5}{|c|}{ Pe amplitude $(\mu \mathrm{V})$} \\
\hline Controls & $-6.49 \pm 5.26$ & $-4.53 \pm 4.66$ & $8.12 \pm 14.23$ & $12.55 \pm 14.33$ \\
\hline ASD & $-2.29 \pm 4.73$ & $-1.48 \pm 5.69$ & $2.14 \pm 8.85$ & $4.66 \pm 9.22$ \\
\hline
\end{tabular}

ASD, autism spectrum disorder; ERN, error-related negativity. Data are means $\pm \mathrm{SD}$.

In addition, there was a main effect of electrode $\left(F_{1,25}=8.62\right.$, $P<0.01)$ with larger amplitudes at Pz. There was no relationship between the Pe and IQ measures or symptom presentation.

\section{Source analyses}

In controls, a one-dipole source model was obtained after source analysis of the ERN for incorrect trials (Fig. 2). The dipole was located in the dorsal region of the ACC and accounted for a large part of the variance in the observed data [ERN location (Cartesian coordinates): $x-0.04, y-0.02, z 0.43$ ); residual variance (RV): 4.6\%; dipole strength: $-67.57 \mathrm{nAm}]$. In children with ASD a one-dipole source model was also obtained. The source was located in a similar location in the ACC $(x-0.07, y-0.05, z 0.51)$, compared with controls, but the variance that this model explained was reduced (RV: 19.6\%) as well as its strength $(-25.87 \mathrm{nAm})$. Extending the model with an extra dipole in children with ASD did not result in a reliable source model. Because a negativity was observed on correct trials as well, the source of this activity was also modelled. In controls the dipole was located in the dorsal region of the ACC (location: $x-0.08, y-0.20, z 0.43$; RV: $7.9 \%$; dipole strength: $-55.01 \mathrm{nAm})$. In children with ASD the source was located in a similar location $(x-0.01, y 0.29, z 0.51)$, but again the variance that this model explained was reduced (RV: $22.7 \%$ ) as well as its strength $(-23.38 \mathrm{nAm})$. Extending the model with an extra dipole in children with ASD did not result in a reliable source model. Because the grand-average average-referenced Pe did not have a clear maximum, neither in ERP amplitude nor global field power, the sources could not reliably be detected.

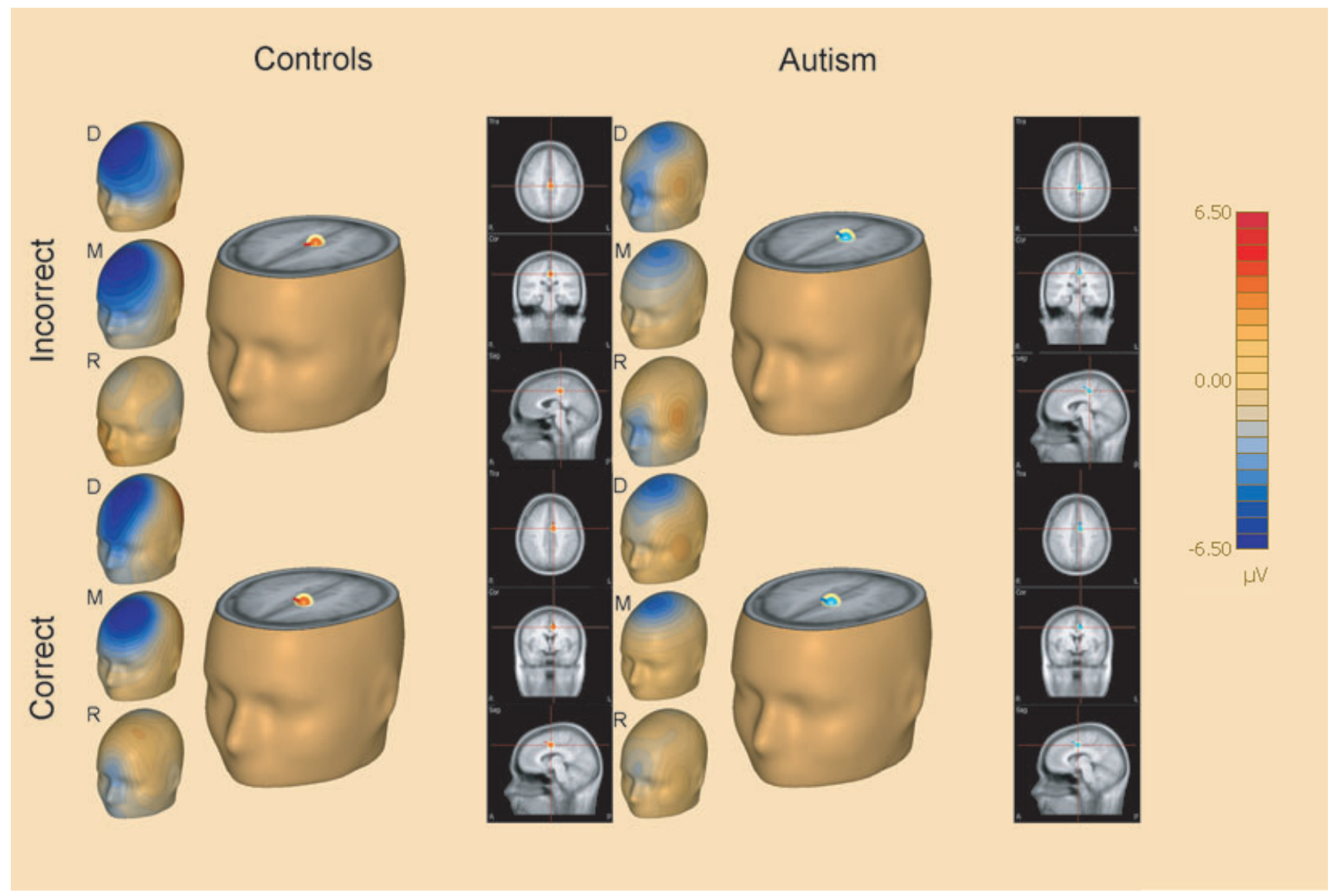

FIG. 2. Dipole source models, derived at ERN peak latency of the average-referenced group-averages for controls (red) and children with ASD (blue) for correct and incorrect responses, projected on a standard realistic MRI head model. The dots in the MRI head models represent source location, whereas the line represents source orientation. The voltage scalp distribution maps (left) indicate: (D) the voltage distribution of the original data, (M) the voltage distribution explained by the model and $(\mathrm{R})$ the residual scalp distribution. Transversal, coronal and sagittal views of the dipole, projected on a standard realistic MRI head model, are shown on the right. All dipoles are located in the ACC region. 


\section{Discussion}

Our study aimed to investigate ACC functioning in children with ASD, compared with age- and IQ-matched controls, by measuring behaviour and ERP activity related to self-monitoring. We found that only control children showed significant post-error slowing, indicating that children with ASD show less adjustment in response strategy after an error. A lack of post-error slowing has been recently reported in adults with ASD as well by Bogte et al. (2007). Error signals provide crucial information for adjustment in a continuously changing environment. The finding that children with ASD do not adjust response strategies according to response outcome might contribute to the enhanced perseverative and rigid behaviour that is characteristic for children with an ASD diagnosis (Lord et al., 1994). Errors of perseveration have been reported before in go-no-go tasks in ASD (Ozonoff et al., 1994).

In addition to post-error slowing, control children showed a significant ERN, which could be localized in the ACC, as has been reported before in other studies (Luu et al., 2000; van Veen \& Carter, 2002; Hermann et al., 2004; O'Connell et al., 2007). A negativity localized to ACC was also seen after correct trials (correct-related negativity; CRN), although it was significantly larger after error trials. Usually, a negativity is present only after incorrect trials, but it has been reported for correct trials as well in dual tasks, like the present task (Pailing \& Segalowitz, 2004). The suggestion is that dual tasks evoke task uncertainty, thereby causing response conflict on both correct and incorrect trials (Pailing \& Segalowitz, 2004). Furthermore, the CRN has been found to be larger in children than adults, which might reflect additional uncertainty about the response (Davies et al., 2004).

Importantly, children with ASD did not show a significant difference in negativity between correct and incorrect trials. This was due to ERN activity, localized in the ACC in both groups, being smaller in children with ASD on incorrect trials. As the ERN was measured as the difference between the positivity preceding and the first negativity following the response, it was verified that these group differences were indeed caused by differences in the negativity and not the positivity. The functional significance of this pre-ERN positive component is unclear. It might reflect stimulus-related P3 activity (Davies et al., 2001), but has also been linked to phasic synchronization of theta activity before response onset (Luu et al., 2004). The difference between ASD children and controls in ERN amplitude can not be explained by differences in the number of error trials as this was comparable between the groups.

In contrast to the present study, a recent study reported larger ERN amplitudes, compared with control children, in children with ASD that had a verbal IQ $>103$ (Henderson et al., 2006). In the present study, however, there was no relationship between verbal IQ, diagnostic group and ERN amplitude. The results of the present study and the study of Henderson et al. (2006) are difficult to compare, because in the latter study a substantial part of the ASD group was on medication as opposed to in the present study. In addition, different tasks were used in both studies. Finally, in the study of Henderson et al. (2006) the Pe was not investigated and no information was provided on the underlying dipole sources.

One possible explanation for the smaller ERN in ASD children in the present study might lie in different experiences of task complexity. In a developmental study, adolescents showed a reduced ERN compared with adults in a complex task, but not in an easy task (Hogan et al., 2005). The authors suggested that increased task demands in the complex task might cause recruitment of other brain regions that influence the ERN generator differently than in easy tasks. However, such an explanation seems unlikely as children with ASD and controls did not differ in RTs and number of errors on the task. Because of the presence of an ERN-like component also on correct trials $(\mathrm{CRN})$, there is growing consensus that, instead of being specific to error detection per se, the ERN is a reflection of continuously active performance-monitoring processes that are enhanced on error trials (Vidal et al., 2000). In line with this, Brown \& Braver (2005) suggest that the primary role of the ACC, the generator of the ERN (Luu et al., 2000; van Veen \& Carter, 2002; Hermann et al., 2004), is the detection of situations in which there is an increased likelihood of making errors rather than error detection in itself. The finding of ACC sources underlying both CRN and ERN in the present study supports such a conclusion. Following the above functional interpretations of CRN, ERN and ACC, the reduced ERN in children with ASD might suggest a specific insensitivity to detect situations in which the chance of making errors is enhanced. This might in turn lead to a failure in the recruitment of coping strategies to deal with this situation, i.e. a failure to allocate more attention, as becomes evident from the lack of posterror slowing in the ASD group.

Besides the reduced ERN, children with ASD also had a reduced Pe response (enhanced positivity to error trials compared with correct trials) compared with age-matched controls. In previous studies including healthy adults, the Pe has been linked to the consciousness or awareness of error processing (Nieuwenhuis et al., 2001; O'Connell et al., 2007). The reduced Pe in children with ASD, therefore, suggests impairments in the conscious processing of the error event. Such reduced error awareness might prevent children with ASD from adapting future behaviour, as reflected in the absence of post-error slowing in children with ASD. Overbeek et al. (2005), however, found limited evidence for a link between the Pe and post-error slowing. Another explanation for the reduced Pe in ASD children might be a reduction in the perceived emotional significance of an error (Overbeek et al., 2005) or it might reflect a general reduction in allocation of attention to important events that is not specific to errors (Jonkman et al., 2007). The latter explanation would be in line with an interpretation of the reduced ERN (in the presence of intact CRN) reflecting an insensitivity to detect situations with increased likelihood of making errors, preventing the recruitment of effective coping strategies.

It is important to view the present results in light of the developmental literature in this field. Several developmental studies have found that typically developing children (Wiersema et al., 2007: 7-8 years; Davies et al., 2004: 7-12 years) show a reduced ERN compared with adults. In addition, several fMRI studies have shown an increase in ACC activation from childhood to adulthood (Adleman et al., 2002). Ladouceur et al. (2007) state that this increase in level of activation may be related to stronger or more synchronous firing of neurons in the ACC, which could explain the increase in ERN amplitude. Alternatively, Ladouceur et al. (2007) suggest that with age the ACC might become more sensitive to errors or response conflict. Others have implicated the late development of the mesensephalic dopamine system, which has been suggested to convey negative reinforcement signals to the frontal cortex, where the ERN is generated in the ACC (Davies et al., 2004; Wiersema et al., 2007).

In light of these developmental findings, the reduced ERN in children with ASD may reflect immaturity or impaired functioning of the ACC and/or connected regions and/or related neurotransmitter systems. This might cause an insensitivity to detect situations, which increased the likelihood of making errors in children with ASD, eventually preventing the recruitment of effective coping strategies. Deficiencies in ACC functioning have been found before in adults with ASD. One study reported decreased metabolism in the 
ACC (Haznedar et al., 1997, 2000) and, two other studies have shown a relation between ACC metabolism and social impairments in ASD (Haznedar et al., 2000; Ohnishi et al., 2000). Future studies should investigate whether deficits in the early stages of error monitoring are present in adults with ASD as well. This might shed light on whether the reduced ERN in children with ASD is a reflection of a developmental delay or might be present during the entire lifespan.

Besides a link to the ACC, the present findings on impaired selfmonitoring as reflected by the ERN and Pe might be linked to the problems of subjects with ASD to meet the requirements of social interactions. Several behavioural features in ASD, like perseverative responding, repetitive behaviours, poor imitation skills and joint attention impairments, may all involve an inability to consistently and accurately monitor ongoing behaviours (Rusell, 1997; Mundy, 2003; Hill, 2004; Henderson et al., 2006). Furthermore, it has been suggested that if children develop difficulties in self-monitoring early in life, they fail to enjoy the normal experiences of being responsible for their actions, resulting in an impoverished sense of self and eventually a failure to develop a normal theory of mind (Rusell \& Jarrold, 1998). Unfortunately we did not find a relationship between the ERN, Pe or post-error slowing and symptom presentation. This might be due to the relatively small sample size and needs further investigation.

Regarding the specificity of the current findings, previous research has indicated reduced post-error slowing and $\mathrm{Pe}$ in children with attention deficit hyperactivity disorder (ADHD), concurrent with a normal ERN (Wiersma et al., 2005; Jonkman et al., 2007), although a reduced ERN in children with ADHD has been reported in another study (Liotti et al., 2005). In patients with schizophrenia normal posterror slowing and Pe have been found, but the ERN has been found to be smaller in size (Mathalon et al., 2002). A similar pattern has been reported for low-socialized adults and children (Santesso et al., 2005). In patients with obsessive-compulsive disorder a normal $\mathrm{Pe}$ and an increased ERN is found (Gehring et al., 2000). Based on these studies, a reduced ERN, Pe and post-error slowing seems to be quite specific to ASD, although there might be overlap with ADHD. Additional research in ASD and ADHD needs to further investigate this suggestion.

Importantly, the sources of the ERN could be located in the ACC area in the present study, in accordance with other studies (Luu et al., 2000; van Veen \& Carter, 2002; Hermann et al., 2004). Therefore, this study provides direct evidence for abnormal ACC activation, related to self-monitoring (i.e. error-monitoring) behaviour in ASD. The higher percentage of RV that remained after source modelling in children with ASD compared with controls might hint to additional activity in brain areas other than the ACC during error processing in children with ASD. It could be that children with ASD show large individual differences in the additional areas they activate during error processing. This might be a reason why it was not possible to fit a second dipole at the group level, and might explain the large RV in the ASD group.

In sum, we found evidence for reduced self-monitoring in ASD as reflected by a reduction in ERN, Pe and post-error slowing. Reduced monitoring (ERN) in the early stages of error processing might be linked to impaired/immature functioning of the ACC and connected regions in $\mathrm{ASD}$, and might reflect an insensitivity to detect situations in which the chance of making errors is enhanced. The reduced Pe in children with ASD probably reflects reduced error awareness or a reduction in allocation of attention to erroneous events. Behaviourally, these deficiencies are reflected in a lack of post-error slowing in children with ASD.

\section{Abbreviations}

ACC, anterior cingulate cortex; ADHD, attention deficit hyperactivity disorder; ASD, autism spectrum disorder; CRN, correct-related negativity EEG, electroencephalogram; ERN, error-related negativity; ERP, eventrelated potential; fMRI, functional magnetic resonance imaging; ISI, interstimulus interval; MEG, magnetoencephalography; $\mathrm{Pe}$, error-related positivity; RT, reaction time; RV, residual variance.

\section{References}

Adleman, N.E., Menon, V., Blasey, C.M., White, C.D., Warsofsky, I.S., Glover, G.H. \& Reiss, A.L. (2002) A developmental fMRY study of the stroop colorword task. Neuroimage, 16, 61-75.

Allman, J.M., Watson, K.K., Tetreault, N.A. \& Hakeem, A.Y. (2005) Intuition and autism: a possible role for von economo neurons. Trends Cogn. Sci., 9 , $367-373$.

American Psychiatric Association. (1994) Diagnostic and Statistical Manual of Mental Disorders, 4th Edn. APA, Washington, DC.

Amiez, C., Joseph, J.P. \& Procyk, E. (2006) Reward encoding in the monkey anterior cingulate cortex. Cereb. Cortex., 16, 1040-1055.

Attneave, F. (1954) Some informational aspects of visual perception. Psychol. Rev., 61, 183-193.

Bogte, H., Flamma, B., van der Meere, J. \& van Engeland, H. (2007) Cognitive flexibility in adults with high functioning autism. J. Clin. Exp. Neuropsychol., 11, 1-9.

Brown, J.W. \& Braver, T.S. (2005) Learned predictions of error likelihood in the anterior cingulate cortex. Science, 307, 1118-1121.

Carter, C.S., Braver, T.S., Barch, D.M., Bovinick, M.M., Noll, D. \& Cohen, J.D. (1998) Anterior cingulate cortex, error detection, and the online monitoring of performance. Science, 280, 747-749.

Coles, M.G.H., Scheffers, M.K. \& Holroyd, C.B. (2001) Why is there an ERN/Ne on correct trials? Response representations, stimulus-related components, and theory of error processing. Biol. Psychol., 56, 173-189.

Davies, P.L., Segalowitz, S.J., Dywan, J. \& Pailing, P.E. (2001) Errornegativity and positivity as they relate to other ERP indices of attentional control and stimulus processing. Biol. Psychol., 56, 191-206.

Davies, P.L., Segalowitz, S.Y. \& Gavin, W.J. (2004) Development of errormonitoring event-related potentials in adolescents. Ann. NY Acad. Sci., 1021, 324-328.

Falkenstein, M., Hoormann, J., Christ, S. \& Hohnsbein, J. (2000) ERP components on reaction errors and their functional significance: a tutorial. Biol. Psychol., 51, 87-107.

Gehring, W.J., Himle, J. \& Nisenson, L.G. (2000) Action-monitoring in obsessive-compulsive disorder. Psychol. Sci., 11, 1-6.

Hajcak, G., McDonald, N. \& Simons, R.F. (2003) To err is autonomic: errorrelated brain potentials, ANS activity, and post-error compensatory behavior. Psychophysiology, 40, 895-903.

Haznedar, M.M., Buchsbaum, M.S., Metzger, M., Solimando, A., SpiegelCohen, J. \& Hollander, E. (1997) Anterior cingulate gyrus volume and glucose metabolism in autistic disorder. Am. J. Psychiatry., 154, 1047-1050.

Haznedar, M., Buchsbaum, M., Wei, T., Hof, P., Cartwright, C., Bienstock, C. \& Hollander, E. (2000) Limbic circuitry in patients with autism spectrum disorders studied with positron emission tomography and magnetic resonance imaging. Am. J. Psychiatry., 157, 1994-2001.

Henderson, H., Schwartz, C., Mundy, P., Burnette, C., Sutton, S., Zahka, N. \& Pradella, A. (2006) Response monitoring, the error-related negativity, and differences in social behavior in autism. Brain. Cogn., 61, 96-109.

Hermann, M.J., Römmler, J., Ehlis, A., Hedrich, A. \& Fallgater, A.J. (2004) Source localization (LORETA) of the error-related-negativity (ERN/Ne) and positivity (Pe). Cogn. Brain. Res., 20, 294-299.

Hill, E.L. (2004) Evaluating the theory of executive dysfunction in autism. Dev. Rev., 24, 189-233.

Hoeksma, M.R., Kemner, C., Verbaten, M.N. \& Van Engeland, H. (2004) Processing capacity in children and adolescents with pervasive developmental disorders. J. Autism Dev. Disord., 34, 341-354.

Hogan, A.M., Vargha-Khadem, F., Kirkham, F.J. \& Baldeweg, T. (2005) Maturation of action monitoring from adolescence to adulthood: an ERP study. Dev. Sci., 8, 525-534.

Jonkman, L.M., van Melis, J.J., Kemner, C. \& Markus, C.R. (2007) Methylphenidate improves deficient error evaluation in children with ADHD: an event-related brain potential study. Biol. Psychol., 76, 217229 . 
Ladouceur, C.D., Dahl, R.E. \& Carter, C.S. (2007) Development of action monitoring through adolescence into adulthood: ERP and source localization. Dev. Sci., 10, 874-891.

Leuthold, H. \& Sommer, W. (1999) ERP correlates of error processing in spatial S-R compatibility tasks. Clin. Neurophysiol., 110, 342-357.

Liotti, M., Pliszka, S.R., Perez, R., Kothmann, D. \& Woldorff, M.G. (2005) Abnormal brain activity related to performance monitoring and error detection in children with ADHD. Cortex, 41, 377-388.

Lord, C., Rutter, M. \& Le Couteur, A. (1994) Autism diagnostic interviewrevised: a revised version of a diagnostic interview for caregivers of individuals with possible pervasive developmental disorders. J. Autism Dev. Disord., 24, 659-685.

Luck, S.J. (2005) An Introduction to the Event-Related Potential Technique. MIT Press, Cambridge, MA.

Luu, P., Flaisch, T. \& Tucker, D.M. (2000) Medial frontal cortex in action monitoring. J. Neurosci., 20, 464-469.

Luu, P., Tucker, D.M. \& Makeig, S. (2004) Frontal midline theta and the errorrelated negativity; neurophysiological mechanisms of action regulation, Clin. Neurophysiol., 115, 1821-1835.

Mathalon, D.H., Fedor, M., Faustman, W.O., Gray, M., Askari, N. \& Ford, J.M. (2002) Response-monitoring dysfunction in schizophrenia: an event-related brain potential study. J. Abnorm. Psychol., 111, 22-41.

Miltner, W.H.R., Lemke, U., Weiss, T., Holroyd, C., Scheffers, M.K. \& Coles, M.G.H. (2003) Implementation of error-processing in the human anterior cingulate cortex: a source analysis of the magnetic equivalent of the errorrelated negativity. Biol. Psychol., 64, 157-166.

Mundy, P. (2003) Annotation: the neural basis of social impairments in autism: the role of the dorsal medial-frontal cortex and anterior cingulate system. J. Child Psychol. Psychiatry., 44, 793-809.

Nieuwenhuis, S., Ridderinkhof, K., Blom, J., Band, G.P.H. \& Kok, A. (2001) Error-related brain potentials are differentially related to awareness of response errors: evidence from an antisaccade task. Psychophysiology, 38, 75-760.

O’Connell, R.G., Dockree, P., Bellgrove, M.A., Kelly, S.P., Hester, R., Garavan, H., Robertson, I.H. \& Foxe, J.J. (2007) The role of cingulate cortex in the detection of errors with and without awareness: a high density electrical mapping study. Eur. J. Neurosci., 25, 2571-2579.

Ohnishi, T., Matsuda, H., Hashimoto, T., Kinihiro, T., Nishikawa, M., Uema, T. \& Sasaki, M. (2000) Abnormal regional cerebral blood flow in childhood autism. Brain, 123, 1838-1844.

Overbeek, T.J.M., Nieuwenhuis, S. \& Ridderinkhof, K.R. (2005) Dissociable components of error processing. On the functional significance of the Pe vis-à-vis the ERN/Ne. J. Psychophysiol., 19, 319-329.
Ozonoff, S., Strayer, D.L., McMahon, W.M. \& Filloux, F. (1994) Executive function abilities in autism and Tourette syndrome: an information processing approach. J. Child. Psychol. Psychiatry., 35, 1015-1032.

Pailing, P.E. \& Segalowitz, S.J. (2004) The effects of uncertainty in error monitoring on associated ERPs. Brain. Cogn., 56, 215-233.

Rabbitt, P.M. (1990) Age, IQ and awareness, and recall of errors. Ergonomics, 33, 1291-1305.

Rusell, J. (1997) How executive disorders can bring about an inadequate theory of mind. In Russell, J. (Ed), Autism as an Executive Disorder. Oxford University Press, Oxford, UK, pp. 256-304.

Rusell, J. \& Hill, E.L. (2001) Action-monitoring and intention reporting in children with autism. J. Child Psychol. Psychiatry., 42, 317-328.

Rusell, J. \& Jarrold, C. (1998) Error correction problems in autism: evidence for a monitoring impairment? J. Autism Dev. Disord., 28, 177-188.

Santesso, D.L., Segalowitz, S.J. \& Schmidt, L.A. (2005) ERP correlates of error monitoring in 10-year olds are related to socialization. Biol. Psychol., 70, 79-87.

Semlitsch, H.V., Anderer, P., Schuster, P. \& Presslich, O. (1986) A solution for reliable and valid reduction of ocular artifacts, applied to the P300 ERP. Psychophysiology, 23, 695-703.

Thomas, D.G., Grice, J.W., Najm-Briscoe, R.G. \& Miller, J.W. (2004) The influence of unequal numbers of trials on comparisons of average event related potentials. Dev. Neuropsychol., 26, 753-774.

Ullsperger, M. \& von Cramon, D.Y. (2001) Subprocesses of performance monitoring: a dissociation of error processing and response competition revealed by event-related fMRI and ERPs. Neuroimage, 14, 13871401.

Ullsperger, M. \& von Cramon, D.Y. (2006) The role of intact frontostriatal circuits in error processing. J. Cogn. Neurosci., 18, 651-664.

van Veen, V. \& Carter, C.S. (2002) The timing of action-monitoring processes in the anterior cingulate cortex. J. Cogn. Neurosci., 14, 593-602.

Vidal, F., Hasbrouc, T., Grapperon, J. \& Bonnet, M. (2000) Is the "error negativity' specific to errors? Biol. Psychol., 51, 109-128.

Wiersma, J.R., van der Meere, J.J. \& Roeyers, H. (2005) ERP correlates of impaired error monitoring in children with ADHD. J. Neural Transm., 112, $1417-1430$.

Wiersema, J.R., van der Meere, J.J. \& Roeyers, H. (2007) Developmental changes in error monitoring: an event-related potential study. Neuropsychologia, 45, 1649-1657.

Yeung, N., Cohen., J.D. \& Botvinick, M.M. (2004) The neural basis of error detection: conflict monitoring and the error-related negativity. Psychol. Rev., 111, 931-959. 